\title{
Similar phenomena, different mechanisms: Semantic and phonological false memories are produced by independent mechanisms
}

\author{
MCKenzie R. Ballou and Mitchell S. Sommers \\ Washington University, St. Louis, Missouri
}

\begin{abstract}
The Deese/Roediger-McDermott paradigm can produce high levels of false remembering for lists of both semantic and phonological associates. The present study investigated whether similar mechanisms mediate false memories with these two types of lists. Experiment 1 measured the relationship between levels of false memory obtained with lists of semantic and phonological associates. The results indicated little correlation between false memories generated with the two types of associates. Experiment 2 used a between-subjects design to determine whether the absence of a significant correlation in Experiment 1 was a consequence of the relatively low levels of false memory observed in that experiment. The results indicated similar proportions of false memories in Experiments 1 and 2, suggesting that the within-subjects design in Experiment 1 did not reduce the overall levels of false recall or recognition. The results are discussed in terms of their implications for the independence of the mechanisms mediating different types of false memories.
\end{abstract}

The Deese/Roediger-McDermott (DRM) paradigm (Deese, 1959; Roediger \& McDermott, 1995) is, by now, a well-established procedure for generating memory errors of commission (false memories). In a typical DRM experiment, participants are presented with lists of words that are all associates of a nonpresented lure (referred to as the critical item, or $C I$ ) and then are tested for recall and recognition of both previously presented list items and the related, but nonpresented, CIs. For example, at study, participants might be presented with a list of items, such as bed, rest, and pillow, which are all semantically related to the nonpresented CI sleep. The general finding from studies employing this paradigm has been that lists of semantic associates produce robust levels of false recall and recognition of the nonpresented but related CIs (Gallo \& Roediger, 2002, 2003; McDermott, 1996; Roediger \& McDermott, 1995; Schacter, Verfaellie, \& Pradere, 1996).

Similar results have been observed when participants are presented with lists of phonological, rather than semantic, associates (Sommers \& Lewis, 1999; Wallace, Stewart, \& Malone, 1995; Wallace, Stewart, Sherman, \& Mellor, 1995; Watson, Balota, \& Sergent-Marshall, 2001). For instance, Sommers and Lewis measured recall and recognition of word lists containing items that differed from a nonpresented $\mathrm{CI}$ by the addition, substitution, or deletion of a single phoneme (e.g., the list items kit, fat, and at are phonologically related to the CI cat). Overall, levels of false memories observed in this study were very similar to those observed in Roediger and McDermott (1995).
The parallel findings obtained in studies of false memories using lists of semantic and phonological associates raise the question of the degree to which the mechanisms producing memory errors of commission for the two list types are similar. We address this question in the present study by using an individual-differences approach to determine whether significant correlations are observed between susceptibility to false memories for lists of semantic and phonological associates. In considering possible outcomes, it is important to note that, because of overlap in experimental methodology and the engagement of general memory functions (i.e., mechanisms common to any tests of recognition and recall), we expect positive correlations between both veridical and false memories generated by the two list types. However, the critical comparison will be with respect to the magnitude of the correlations. We expect that tests of veridical memory will engage similar mechanisms for the semantic and phonological lists, reflecting considerable (but not complete) overlap in recognition and recall of the two types of associates. If there is a similar degree of overlap in the mechanisms mediating false memories for the two types of associates, we would expect significant (i.e., nonzero) correlations between false memories generated with lists of phonological and semantic associates and a nonsignificant difference in the magnitude of correlations between veridical and false memories across list types. In contrast, if there is significantly less overlap in the mechanisms underlying false memories than in those underlying veridical memories for the two list types, we would expect (1) that the cor-

M.S.Sommers, msommers@wustl.edu 
relation between false memory for the two list types will not be significantly greater than zero and (2) that correlations between veridical memories will be significantly greater than correlations between false memories for the two types of associates. Thus, the relationship between false memory for semantic and phonological lists will be considered relative to the magnitude of the relationship between veridical memories for the two list types.

\section{Reasons for Expecting Significant Correlations Between Semantic and Phonological False Memories}

In their initial demonstration of the DRM paradigm using lists of semantic associates, Roediger and McDermott (1995) suggested that, when participants are presented with lists of semantically related items, activation spreads from each list item to the nonpresented CI. Within this framework, false memories occur because activation accumulates on the nonpresented CI and participants cannot distinguish this internally generated activation from activation produced by presentation of the list items (see also Underwood, 1965). Findings from more recent studies (Balota et al., 1999; Gallo \& Roediger, 2002; McDermott \& Watson, 2001; Roediger, Balota, \& Watson, 2001; Watson, Balota, \& Roediger, 2003) generally have supported the proposal that spreading activation within a semantic network is an important factor in generating false memories with lists of semantic associates.

A similar framework has been used to account for false memories generated with lists of phonological associates (Sommers \& Lewis, 1999). Specifically, most current models of spoken word recognition (Luce \& Pisoni, 1998; Marslen-Wilson, 1987; Norris, 1994) suggest that presentation of a word initially activates a set of candidate items (including the target) and that word recognition proceeds by reducing activation on candidate items that are no longer consistent with the unfolding input. Thus, just as false memories with lists of semantic associates are proposed to result from spreading activation within semantic networks, spreading activation within phonological networks has been shown to contribute to false memories generated with lists of phonological associates (Sommers \& Huff, 2003; Sommers \& Lewis, 1999).

Studies examining the effects of normal aging on the incidence of false memories (Balota et al., 1999; Budson, Sullivan, Daffner, \& Schacter, 2003; Waldie \& Kwong See, 2000; Watson et al., 2001) provide a second set of findings consistent with overlap in the mechanisms producing semantic and phonological false memories. Budson et al., for example, reported that normal aging increased the incidence of false recognition for lists of both semantic and phonological associates. Moreover, the proportion of false recognition for semantic and phonological associates was remarkably similar in both young (.44 for semantic and .47 for phonological) and older (.67 for both list types) adults (see also Watson et al., 2001).

Additional evidence for overlap in the mechanisms mediating semantic and phonological false memories are findings from studies examining the effects of presentation duration (of each list item) on the probability of obtaining false memories (McDermott \& Watson, 2001). McDermott and Watson measured false recall for lists of semantic and phonological associates for presentation durations of 20, 250, 1,000,3,000, and 5,000 msec. With the exception of the 20-msec duration for phonological lists (which may have strongly encouraged guessing), the function relating recall probability of the CI to presentation duration was quite similar for both list types - generally exhibiting a significant decrease from 250 to $1,000 \mathrm{msec}$ and a steady, but shallower, decline for longer presentations. McDermott and Watson also reported highly similar serial position curves for semantic and phonological CIs, and this similarity was observed across all but the fastest (20-msec) presentation rate.

\section{Reasons for Expecting Nonsignificant Correlations Between Semantic and Phonological False Memories}

Despite the similarity in empirical findings and theoretical accounts for phonological and semantic false memories, other evidence suggests that the mechanisms mediating the two types of memory errors are largely independent. For example, Watson et al. (2003) proposed that lists of semantic associates might generate false memories via conceptually based spreading activation, whereas lists of phonological associates might produce false memories through perceptually based activation. To test this proposal, Watson et al. (2003) presented participants with DRM lists for nonpresented CIs (e.g., dog) consisting of either semantic associates only (e.g., hound, puppy) or phonological associates only (e.g., dot, $\log$ ) or with hybrid lists consisting of both phonological and semantic associates (e.g., dot, puppy). Watson et al. (2003) reasoned that if activation adds linearly across different types of codes (conceptual and perceptual) to produce false memories, then levels of false recall in the hybrid lists should be predictable from the levels obtained in the pure lists (semantic only and phonological only). On the other hand, if different mechanisms mediate phonological and semantic false memories, overadditive levels of false memory might be predicted for the hybrid condition. Consistent with the latter prediction, Watson et al. (2003) reported that across three experiments, combining lists of phonological and semantic associates produced overadditive levels of both false recall and recognition. Thus, the findings of Watson et al. (2003) suggest at least partial independence in the mechanisms mediating phonological and semantic false memories.

It is also interesting to note that a number of studies have found differences in the subjective experience of false memories generated by lists of phonological and semantic associates. Using the remember/know paradigm (Tulving, 1985), studies of false recognition (Geraci \& McCabe, 2006; Schacter, Verfaellie, \& Anes, 1997; Sommers \& Huff, 2005) generally report a majority of remember responses to CIs from lists of semantic associates, whereas know responses dominate false recognition of CIs from lists of phonological associates. One interpretation of these findings is that activation from semantic associates directs attention to deeper, conceptual-level rela- 
tions among the associates, thereby producing more vivid "memories" of the nonpresented CI and, hence, more remember responses. Lists of phonological associates, on the other hand, may produce shallower levels of processing based on surface features leading to less vivid false recognition and, hence, more know responses.

The main purpose of the present set of experiments was to provide a more direct assessment of whether semantic and phonological false memories are mediated by similar or distinct mechanisms. In Experiment 1, participants were tested for memory of both phonologically and semantically related lists. This within-participants design allowed us to use an individual-differences approach to determine whether the probability of obtaining false memories for one type of list was predictive of false recall and recognition with the other list type. Significant correlations between semantic and phonological false memories would suggest overlap in the mechanisms mediating memory errors with the two types of associates. Conversely, the absence of a correlation between false memories generated with lists of semantic and phonological associates would be more consistent with the claim (Watson et al., 2003) of at least partial independence in how the two types of memory errors are generated.

\section{EXPERIMENT 1}

\section{Method}

Participants. Fifty-six native English-speaking undergraduates from the Washington University student participant pool volunteered for Experiment 1. All participants received course credit for their participation and reported no speech or hearing disorders.

Materials. Twenty-four lists of 15 associates were selected as study material for Experiment 1. Twelve lists contained words that were all phonologically associated to their respective CIs (Sommers \& Lewis, 1999). The remaining 12 lists were composed of words semantically associated to their respective CIs (Stadler, Roediger, $\&$ McDermott, 1999). Each list item appeared on only one list. The order of items within each list was randomized once prior to conducting the experiment, and this order was used for all participants. The use of an individual-differences approach required that all participants receive the lists in the same order. Therefore, list order was also randomized once, with the exception that no more than three lists of a given type (semantic or phonological) could be presented consecutively, and this order was used for all participants.

A 144-item list was also developed for a final recognition test. Seventy-two of the test items were from the study lists ( 3 from each of the 24 lists) and are referred to as "old" items because they were presented at study; the 72 test items not included in the lists are referred to as "new" items. These new items were composed of the 24 CIs from the studied lists (12 semantic, 12 phonological) and 48 items from lists in Sommers and Lewis (1999) and Stadler et al. (1999) that were not selected for study in this experiment. Of the latter 48 new items, 12 were CIs from nonpresented lists (6 semantic, 6 phonological) and 36 were list items from nonpresented lists (3 items each from the 12 lists). In all, half of the items were old, half were new, half were taken from phonological lists, and half were taken from semantic lists.

The study lists and recognition test items in both of the present experiments were presented simultaneously in the auditory and visual modalities. For the auditory presentations, all words were recorded by a male talker and digitized online at $44.1 \mathrm{kHz}$ (16 bit). Rootmean-squared (RMS) amplitude was equated for all stimuli, which were presented at approximately $75 \mathrm{~dB}$ SPL over matched and calibrated headphones. For the visual presentations, participants viewed the orthographic representations of each word on a computer screen from approximately $0.5 \mathrm{~m}$.

Design and Procedure. In Experiment 1 , half $(n=28)$ of the participants performed a free recall task following each study list presentation. For this task, a within-subjects design was used with list type (semantic vs. phonological associates) as the independent variable and proportion of study items, CIs, and extra-list intrusions recalled as the dependent measures. Participants were told that they would be presented with several lists of words for study and that after each list presentation their task was to write down as many words as possible from the previously presented list. Participants were instructed not to recall an item "unless [they] were fairly certain that it had been presented on the immediately preceding list." At the beginning of each list, participants heard a warning tone and saw "get ready for list X" on the computer screen, where X corresponded to the present list number (1-24). After a 1-sec interstimulus interval (ISI), the first list item appeared on the screen and, simultaneously, was presented over the headphones. Each item remained on the screen for $1.5 \mathrm{sec}$ and was followed by a 750-msec ISI. After the final list item had been presented, participants were given $90 \mathrm{sec}$ to recall the items and write them on numbered response sheets. Participants were told that they could recall the items in any order.

Participants not performing free recall $(n=28)$ instead performed a filler task of math problems. The procedure for these participants was the same as that in the recall condition; however, instead of performing free recall during the 90 -sec period after each list presentation, participants were instructed to complete as many math problems as they could from a booklet of addition and subtraction problems.

Immediately following the recall task or math problems for the final list, all participants were given the 144-item old/new recognition task. For this task, the list type from which each item was taken (semantic vs. phonological) was the independent variable, and the proportion of study items, CIs, and foils called "old" were the dependent measures. Items were presented one at a time (again both spoken and orthographic) in the same randomly determined order for each participant. Participants were instructed to make an "old" judgment for any item they were "reasonably certain had been presented on an earlier list" and to make a "new" judgment for items that had not been presented on an earlier list.

\section{Results}

Recall. Table 1 displays the mean proportion of studied items, CIs, and intruding items recorded by participants in Experiment 1. The values for studied items and CIs were calculated as proportions of the total possible items in each category (180 for studied items and 12 for CIs). Intruding items, however, were calculated as a proportion of the total number of items recorded for each participant. A 2 (list type: semantic vs. phonological) $\times 3$ (item type: studied, $\mathrm{CI}$, intruding) within-subjects ANOVA revealed a main effect of item type $\left[F(2,54)=201.9, M S_{\mathrm{e}}=.017, p<.001\right]$. Pairwise tests (this and all subsequent pairwise tests were Fischer's LSD adjusted, $\alpha=.05$ ) revealed that the proportion of studied items, collapsed across list type ( $M=.55$, $S E=.02)$, was greater than the proportion of CIs $(M=$

Table 1

Mean Proportions of Studied Items, Critical Items, and Intruding Items Recalled for Experiment 1

\begin{tabular}{|c|c|c|c|c|c|c|}
\hline \multirow[b]{2}{*}{ List Type } & \multicolumn{2}{|c|}{ Studied Items } & \multicolumn{2}{|c|}{ Critical Items } & \multicolumn{2}{|c|}{ Intruding Items } \\
\hline & $M$ & $S E$ & $M$ & $S E$ & $M$ & $S E$ \\
\hline Semantic & .64 & .08 & .20 & .17 & .04 & .03 \\
\hline Phonological & .46 & .10 & .27 & .16 & .08 & .05 \\
\hline
\end{tabular}


$.24, S E=.03$ ), which was greater than the intrusion rate $(M=.06, S E=.01)$. The two-way interaction between list type and item type also reached significance $[F(2,54)=$ $\left.33.4, M S_{\mathrm{e}}=.008, p<.001\right]$. Pairwise tests revealed that the proportion of studied items recalled was greater for semantic lists than for phonological lists, whereas for intruding items, the rate was higher for phonological than for semantic lists. The difference between semantic and phonological CIs did not reach significance.

In order to ensure that the pattern of results observed for studied items and CIs was not influenced systematically by differences in the rates of intruding items, we conducted a 2 (list type: semantic, phonological) $\times 2$ (item type: studied items and CIs) within-subjects ANCOVA, with intrusion rates for semantic and phonological lists as the covariates. The pattern of results for studied items and CIs remained unchanged, with higher recall of studied items for semantic than for phonological lists, but with no difference in recall rates for CIs.

To determine the relationship between recall (both veridical and false) across the two list types, Pearson product-moment correlations were calculated for each response type between the phonological and semantic lists. Recall of studied items $(r=.80, p<001)$ and intrusion rates $(r=.59, p<.001)$ were highly correlated across lists of semantic and phonological associates. However, the correlation for recall of CIs across semantic and phonological lists was small and failed to reach significance $(r=.24, p=.23)$. To compare the magnitude of the correlations, we used Steiger's (1980) formula for testing the difference between two dependent correlations. The analysis revealed that the correlation between recall of CIs for the two list types (.24) was significantly lower than the correlation between veridical recall for the two list types $(.80 ; z=2.7, p<.05)$. Furthermore, the correlation between semantic and phonological false recall was also significantly lower than the correlation between intrusion rates $(z=2.1, p<.05)$. Finally, the correlation between veridical recall for the two list types did not differ significantly from the correlation between intrusion rates for the two list types.

In addition to measuring correlations for false recall of the CI across lists of semantic and phonological associates, we also computed correlations between veridical and false recall for each list type. A priori, better memory for studied items might be expected to reduce overall levels of false recall because participants would be able to use memory for presented items to aid in accurately attrib- uting activation on a CI to prior presentation of associates rather than to actual list presentation (Gallo, 2004; Kensinger \& Schacter, 1999). Of particular interest to the present study is whether a similar pattern of correlations between veridical and false memory would be observed for the two types of lists. The correlation between veridical and false recall for lists of semantic associates was significant $(r=-.41, p<.01)$, whereas the same correlation was not significant for lists of phonological associates $(r=-.11, p=.41)$. Comparison of the magnitude of the correlations indicated that the two correlations did not differ significantly from one another. These findings suggest that although there is a general trend for an inverse relationship between false and veridical recall for both types of associates, the relationship between accurate recall of list items and false recall of CIs is similar for semantic and phonological lists.

Recognition after recall. Table 2 displays the mean proportion of hits to studied items, false alarms to CIs, and false alarms to foils from semantic and phonological lists for the final recognition task following recall. A 2 (list type: semantic, phonological) $\times 3$ (item type: studied item, CI, foil) within-subjects ANOVA revealed a main effect of list type $\left[F(1,27)=15.5, M S_{\mathrm{e}}=.038\right.$, $p<.001$ ], indicating that, overall, a greater proportion of test items from semantic lists $(M=.53, S E=.02)$ than from phonological lists $(M=.41, S E=.03)$ were called "old." The main effect of item type also reached significance $\left[F(2,54)=216.9, M S_{\mathrm{e}}=.02, p<.001\right]$. Pairwise comparisons indicated that the proportion of studied items $(M=.70, S E=.03)$ called "old" was greater than the proportion of CIs $(M=.55, S E=.04)$ called "old" and that the proportion of CIs labeled "old" was greater than the false alarm rate to foils $(M=.15, S E=.02)$. Finally, the two-way list type $\times$ item type interaction also reached significance $\left[F(2,54)=8.9, M S_{\mathrm{e}}=.02, p<.001\right]$. Pairwise comparisons revealed that both veridical and false recognition of CIs were higher for lists of semantic than for lists of phonological associates. The difference between semantic and phonological foils, however, did not reach significance $(p>.2)$.

To determine whether the pattern of results observed for studied items and CIs was the result of systematic differences in the rates of false alarms to foils, corrected recognition scores were calculated for studied items and CIs. Corrected recognition rates for studied items were obtained by subtracting the proportion of new list items called "old" from the proportion of studied items called

Table 2

Mean Corrected and Uncorrected Proportions of Studied Items, Critical Items (CIs), and Foils Called "Old" in Recognition After Recall From Experiment 1

\begin{tabular}{|c|c|c|c|c|c|c|c|c|c|c|}
\hline \multirow[b]{2}{*}{ List Type } & \multicolumn{2}{|c|}{ Studied } & \multicolumn{2}{|c|}{$\mathrm{CI}$} & \multicolumn{2}{|c|}{ Foils } & \multicolumn{2}{|c|}{$\mathrm{C}-$ Studied } & \multicolumn{2}{|c|}{$\mathrm{C}-\mathrm{CI}$} \\
\hline & $M$ & $\overline{S E}$ & $M$ & $\overline{S E}$ & $M$ & $\overline{S E}$ & $M$ & $\overline{S E}$ & $M$ & $\overline{S E}$ \\
\hline Semant & .79 & .02 & .64 & .04 & .14 & .02 & .62 & .03 & .58 & .05 \\
\hline Phonological & .60 & .03 & .46 & .06 & .16 & .02 & .45 & .03 & .29 & .05 \\
\hline
\end{tabular}

Note $-\mathrm{C}-$ studied $=$ proportion of studied items called "old" minus the proportion of new list items called "old." C - CI = proportion of CIs called "old" minus the proportion of new CIs called "old." 
"old." Corrected recognition for CIs was calculated by subtracting the proportion of control CIs (i.e., CIs from lists not presented at study) called "old" from the proportion of list CIs called "old” (Kensinger \& Schacter, 1999). These corrected values are presented in the final two columns of Table 2. A 2 (list type) $\times 2$ (item type) ANOVA revealed that the pattern of results observed in the uncorrected data was preserved using the corrected scores.

As with the recall data, Pearson product-moment correlations were calculated for each response type (hit, false alarm to CI, false alarm to foil) between semantic and phonological lists. Semantic and phonological lists correlated with one another for studied items $(r=.62, p<$ $.001)$ and foils $(r=.52, p<.01)$. As with recall, however, the correlation between semantic and phonological lists for CIs was small and failed to reach significance $(r=$ $.10, p=.61)$. Tests for the difference between dependent correlations indicated significant differences between the correlations for hits and false recognition of CIs $(z=2.4$, $p<.05)$ across the two list types and significant differences between the correlations for false alarms to foils and false alarms to CIs $(z=2.0, p<.05)$ across list type. However, no significant difference was observed between the magnitude of the correlations between hits and between false recognition of CIs across the two list types.

Measures of the relationship between veridical and false recognition for the two types of associates yielded a somewhat different pattern than was observed for recall. Specifically, we found a significant correlation between correct recognition of studied items and false recognition of CIs for the phonological lists $(r=-.41, p<.05)$ and a nonsignificant correlation for the semantic lists $(r=$ $-.21, p>.2$ ). Similar to the recall data, however, comparison of the magnitude of the correlations indicated no significant difference.

Recognition without prior recall. One concern with the recognition results in Table 2 is that recognition always followed recall and it is unclear to what extent prior recall of list items may have influenced the recognition results. To address this issue, Table 3 displays the mean proportion of studied items, CIs, and foils called "old" in the final recognition task for the group that completed math problems, rather than performing recall following list presentation. A 2 (list type) $\times 3$ (item type) within-subjects ANOVA revealed only a main effect of item type $[F(2,54)=106.4$, $\left.M S_{\mathrm{e}}=.02, p<.001\right]$. Pairwise tests revealed that both proportion of studied items $(M=.58, S E=.03)$ and CIs
$(M=.56, S E=.03)$ called "old" were greater than the proportion of foils $(M=.26, S E=.03)$ called "old." The proportion of hits to studied items and false alarms to CIs were not significantly different from one another $(p>.15)$. Neither the main effect of list type nor the list type $\times$ item type interaction reached significance.

Corrected recognition scores for studied items and CIs were also calculated and are presented in the final two columns of Table 3 . A 2 (list type) $\times 2$ (item type) ANOVA revealed a significant interaction between list type and item type $\left[F(1,27)=5.2, M S_{\mathrm{e}}=.03, p<.05\right]$. Pairwise tests revealed that the corrected CI values were greater for semantic lists than for the phonological lists. The difference between semantic and phonological lists for studied items was not significant $(p>.7)$. Furthermore, the main effects of item type and list type did not reach significance $(p>.05)$.

The pattern of correlations observed earlier between semantic and phonological lists was again observed in the recognition without recall task. Semantic and phonological lists correlated with one another for studied items $(r=.52, p<.01)$ and foils $(r=.71, p<.001)$. However, the correlation between semantic and phonological CIs was again small and failed to reach significance $(r=.27$, $p=.16)$. Comparison of the magnitude of the correlations indicated marginally significant differences between the correlation of hits and the correlation for false alarms to the CI $(z=1.89, p<.08)$ and significant differences between the correlation for false alarms to foils and false alarms to CIs across the two types of lists $(z=2.1, p<$ $.05)$. No differences were obtained between the correlation for false alarms and the correlation for hits.

Finally, correlations between veridical and false recognition for the two list types were also similar to those obtained for the recognition without prior recall. Pearson product-moment correlations between correct recognition of studied items and false recognition of CIs were -.54 and -.37 ( $p<.05$ for both) for the phonological and semantic lists, respectively. Comparison of the two correlations, however, indicated no significant difference in the magnitude of the relationships.

\section{Discussion}

Overall, the results of Experiment 1 provide, to our knowledge, the first direct evidence for minimal overlap in the mechanisms responsible for semantic and phonological false memories. Specifically, the pattern of corre-

Table 3

Mean Corrected and Uncorrected Proportions of Studied Items, Critical Items (CIs), and Foils Called "Old" in Recognition Without Prior Recall From Experiment 1

\begin{tabular}{|c|c|c|c|c|c|c|c|c|c|c|}
\hline \multirow[b]{2}{*}{ List Type } & \multicolumn{2}{|c|}{ Studied } & \multicolumn{2}{|c|}{ CI } & \multicolumn{2}{|c|}{ Foils } & \multicolumn{2}{|c|}{$\mathrm{C}-$ Studied } & \multicolumn{2}{|c|}{$\mathrm{C}-\mathrm{CI}$} \\
\hline & $M$ & $S E$ & $M$ & $S E$ & $M$ & $S E$ & $M$ & $S E$ & $M$ & $S E$ \\
\hline Semant & .58 & .04 & .60 & .04 & .25 & .03 & .32 & .04 & .38 & .06 \\
\hline Phonological & .58 & .03 & .52 & .04 & .28 & .03 & .31 & .02 & .22 & .04 \\
\hline
\end{tabular}

Note - C - studied $=$ proportion of studied items called "old" minus the proportion of new list items called "old." C - CI = proportion of CIs called "old" minus the proportion of new CIs called "old." 
lations for recall, recognition without prior recall, and recognition following prior recall was consistent; significant correlations between semantic and phonological lists were observed for studied items and items other than the CIs. In contrast, correlations between rates of false memory to the two types of CIs were small and nonsignificant. Small to moderate correlations (negative) were observed between veridical and false memory, but differences between these correlations for semantic and phonological lists generally did not reach significance.

One potential concern with the findings from Experiment 1 is that the levels of false remembering for both the semantic and phonological lists were somewhat low, as compared with what has been observed previously with similar lists (McDermott, 1996; Roediger \& McDermott, 1995; Schacter et al., 1996; Sommers \& Huff, 2003; Sommers \& Lewis, 1999). For example, Roediger and McDermott reported false recall and recognition rates of 55\% and $81 \%$, respectively, for CIs generated by lists of semantic associates. Sommers and Lewis obtained 54\% percent false recall and 69\% false recognition for CIs generated by lists of phonological associates. Rates of false recall and recognition in Experiment 1 were generally 20\%-30\% lower than these values.

The main difference between the earlier false memory studies and the procedure used in Experiment 1 is that participants in the present study received both list types, whereas in the earlier studies, participants generally received only one type of list. It is possible that presentation of both list types in Experiment 1 highlighted the relationship between items within a list (i.e., made it more apparent that list items were either semantically or phonologically related) and this increased the likelihood that participants would adopt strategies to reduce false memories. For example, in some instances, participants may have been able to determine the $\mathrm{CI}$ for a given list and use that information to avoid false recall and recognition of that item. Of particular concern is the possibility of an asymmetry between semantic and phonological lists in terms of either the likelihood of applying strategies to reduce false remembering (i.e., participants may have been more likely to use these strategies for one list type) or the effectiveness of such strategies (e.g., identification of the CI may have been easier for one list type). If these or other asymmetries were present in Experiment 1, the absence of a correlation between semantic and phonological false memories may be due to differences in strategic processing rather than to the absence of a mechanism common to both phenomena.

Alternatively, several studies have documented that the lists of phonological and semantic associates used in previous studies vary considerably in their ability to generate false recall and recognition (Sommers \& Lewis, 1999; Stadler et al., 1999), and the lower levels of false remembering in the present study may simply reflect the particular set of lists used. In order to address this issue, Experiment 2 used a between-subjects design in which participants received only one list type. Similar levels of false memory across Experiments 1 and 2 would reduce the likelihood that asymmetries in strategic processing, owing perhaps to the presentation of both list types, contributed to the lack of correlation between semantic and phonological false memories.

\section{EXPERIMENT 2}

\section{Method}

Participants. Fifty-four Washington University undergraduate students volunteered for Experiment 2. All received course credit for their participation and met the same criteria as participants in Experiment 1. There was no overlap in participants across the two experiments.

Materials and Procedure. The phonological and semantic lists used in Experiment 2 were the same as those used in Experiment 1. The procedure for Experiment 2 was identical to the recall-plusrecognition condition in Experiment 1. Participants in Experiment 2 received either the 12 phonological or 12 semantic lists for study, were tested for recall following each list, and were given a final old/ new recognition test after all 12 lists had been presented.

\section{Results}

Recall. Table 4 displays the mean proportion of studied items, critical items, and intruding items for the recall task. A 2 (list type) $\times 3$ (item type) mixed ANOVA with list type as the between-subjects variable revealed a main effect of list type $\left[F(1,52)=6.6, M S_{\mathrm{e}}=.01, p<.01\right]$ and a main effect of item type $\left[F(2,104)=321.6, M S_{\mathrm{e}}=.01\right.$, $p<.001]$. Pairwise tests revealed that recall was higher for studied items $(M=.56, S E=.01)$ than for CIs $(M=.21$, $S E=.02)$ and that more CIs than intruding items $(M=$ $.03, S E=.01)$ were recalled. Lastly, a list type $\times$ item type interaction was observed $\left[F(2,104)=13.5, M S_{\mathrm{e}}=.01\right.$, $p<.001]$. Pairwise tests revealed that the group receiving lists of semantic associates recalled a greater proportion of studied items than did participants who received lists of phonological associates, but that the phonological list group produced greater proportions of intruding items than did the semantic list group. No significant betweengroup differences were observed for false recall of CIs.

In order to assess whether systematic differences in the proportion of intruding items contributed to the pattern of results obtained for studied items and CIs, a 2 (list type) $\times$ 2 (item type) mixed ANCOVA was conducted, with list type as the between-subjects factor and proportion of intruding items (both phonological and semantic) as the covariates. The test did not reveal a pattern for studied items and CIs that was different from that observed in the original ANOVA.

Finally, it is interesting to note that the same dissociation that was observed for the correlations between veridical and false recall in Experiment 1 was maintained

Table 4

Mean Proportions of Studied, Critical, and Intruding Items Recalled for Experiment 2

\begin{tabular}{|c|c|c|c|c|c|c|}
\hline \multirow[b]{2}{*}{ List Type } & \multicolumn{2}{|c|}{ Studied Items } & \multicolumn{2}{|c|}{ Critical Items } & \multicolumn{2}{|c|}{ Intruding Items } \\
\hline & $M$ & $S E$ & $M$ & $S E$ & $M$ & $S E$ \\
\hline Semanti & .64 & .02 & .21 & .03 & .02 & .01 \\
\hline Phonological & .47 & .02 & .22 & .03 & .05 & .01 \\
\hline
\end{tabular}


in Experiment 2. The correlation between (correct) recall of studied items and (false) recall of CIs was significant for participants who received the lists of semantic associates $(r=.42, p<.05)$, but not for participants who received the lists of phonological associates $(r=.03$, $p>.9$ ). Comparison of the magnitude of the correlations indicated that the difference between the two correlations did not reach significance.

Recognition after recall. Table 5 displays the recognition results for Experiment 2. A 2 (list type) $\times 2$ (item type) mixed ANOVA with list type as the between-subjects variable revealed a main effect of item type $[F(2,104)=$ $\left.263.5, M S_{\mathrm{e}}=.023, p<.001\right]$. Pairwise tests revealed significantly higher veridical recognition $(M=.73, S E=$ $.02)$ than false recognition of CIs $(M=.50, S E=.01)$, and that a greater proportion of CIs than foils $(M=.07, S E=$ $.01)$ was called "old." The main effect of list type also reached significance $\left[F(1,52)=4.59, M S_{\mathrm{e}}=.043, p<\right.$ $.05]$, indicating that overall more semantic than phonological items were called "old." Finally, the list type $\times$ item type interaction reached significance $[F(2,104)=8.63$, $\left.M S_{\mathrm{e}}=.023, p<.001\right]$. Pairwise tests revealed that a greater proportion of studied items and CIs were called "old" for semantic lists as opposed to phonological lists, but that false recognition of foils was greater for lists of phonological than for lists of semantic associates.

To make certain that the pattern of results observed for studied items and CIs was not affected systematically by differences in participants' tendency to call items "old," corrected values for studied items and CIs are presented on the right side of Table 5. A 2 (list type) $\times 2$ (item type) mixed ANOVA with list type as the between-subjects variable was conducted with these corrected values. The pattern of results revealed by this analysis was the same as that observed for the uncorrected studied items and CIs.

\section{Discussion}

Overall, the results of Experiment 2 closely mirror those of Experiment 1 for both recall and recognition. Of particular importance to the present study, the proportion of false memories observed using the between-subjects design was very similar to that observed using a withinsubjects design. These findings suggest that the use of a within-subjects design in Experiment 1 did not reduce the overall levels of false recall or recognition. Although such findings do not completely rule out asymmetries in strategic processing across lists of phonological and semantic associates, they do suggest that the failure to find signif- icant correlations between the two list types in Experiment 1 was not a consequence of the within-participants design, differentially reducing overall levels of false remembering for the two types of associates.

\section{GENERAL DISCUSSION}

The findings from the present experiments support the proposal that the mechanisms responsible for producing semantic false memories are largely independent from those responsible for producing phonological false memories. Correlations between false recall and recognition of CIs across the two types of lists were not significant. In contrast, significant correlations were observed between semantic and phonological lists for veridical memory and memory errors for unrelated items. The finding that this pattern replicated across tasks (recall, recognition with prior recall, recognition without prior recall) lends support to the Watson et al. (2003) claim of differences in the mechanisms responsible for semantic and phonological false memories. Finally, similar levels of veridical and false memory were observed for both within- and between-participants designs, suggesting that the observed pattern of correlations in Experiment 1 was not the result of the within-participant design promoting asymmetric use of strategic processing across the two list types.

Within the activation-monitoring framework (Balota et al., 1999; Roediger et al., 2001) false memories in the DRM paradigm are a consequence of (1) spreading activation from representations of list items to representations of the CI, (2) activation accruing on the CI from this repeated spreading activation, and (3) failure to distinguish the source of activation on CIs as resulting from spreading activation rather than from list presentation. Thus, within the activation-monitoring framework, the absence of a significant correlation between false memories for semantic and phonological associates could be accounted for by differences in the nature of spreading activation from phonological as opposed to semantic lists, differences in participants' ability to monitor phonological versus semantic levels of activation, or a combination of both activation and monitoring.

The mechanisms mediating both semantic and phonological false memories are an area of active investigation, making any discussion of differences in the mechanisms responsible for these two types of memory errors necessarily speculative. Nevertheless, a number of recent findings (Ballardini, Yamashita, \& Wallace, 2008; Chan,

Table 5

Mean Corrected and Uncorrected Proportions of Studied Items, Critical Items (CIs), and Foils Called "Old" in Experiment 2

\begin{tabular}{|c|c|c|c|c|c|c|c|c|c|c|}
\hline \multirow[b]{2}{*}{ List Type } & \multicolumn{2}{|c|}{ Studied } & \multicolumn{2}{|c|}{$\mathrm{CI}$} & \multicolumn{2}{|c|}{ Foils } & \multicolumn{2}{|c|}{$\mathrm{C}-$ Studied } & \multicolumn{2}{|c|}{$\mathrm{C}-\mathrm{CI}$} \\
\hline & $M$ & $S E$ & $M$ & $S E$ & $M$ & $S E$ & $M$ & $S E$ & $M$ & $S E$ \\
\hline Semantic & .80 & .02 & .57 & .05 & .04 & .01 & .77 & .02 & .51 & .06 \\
\hline Phonological & .66 & .16 & .43 & .24 & .11 & .02 & .56 & .03 & .31 & .04 \\
\hline
\end{tabular}

Note $-\mathrm{C}-$ studied $=$ proportion of studied items called "old" minus the proportion of new list items called "old." $\mathrm{C}-\mathrm{CI}=$ proportion of CIs called "old" minus the proportion of new CIs called "old." 
McDermott, Watson, \& Gallo, 2005; Watson et al., 2003) suggest that differences in the nature of activation that results from presenting lists of semantic versus phonological associates is a likely contributor to the absence of correlations between these two types of memory errors. As noted in the introduction, Watson et al. (2003) found that levels of false memory for hybrid lists (lists containing both phonological and semantic associates of the $\mathrm{CI}$ ) were overadditive relative to what would have been expected on the basis of rates obtained from phonological-only or semantic-only lists. Watson et al. (2003) suggested that this overadditive effect was a consequence of qualitative differences in the nature of spreading activation in the two lists types: perceptually based activation in the case of phonological associates versus conceptually based activation when semantic associates are presented. According to this proposal, when participants receive lists of phonologically related words, activation spreads to items related on the basis of surface features, such as articulatory gestures (e.g., similarity in voicing, place, or manner) and phonemes. For lists of semantic associates, however, activation is more conceptually or semantically driven, with greater dependence on lexical as opposed to perceptual processing.

One set of findings that is consistent with differences in the nature of activation as a factor contributing to low correlations between semantic and phonological false memories comes from a recent investigation (Ballardini et al., 2008) examining phonological and semantic false memories as a function of presentation duration. Of particular interest for the present study is a comparison of the levels of false memory obtained at the shortest $(20 \mathrm{msec})$ and longest $(250 \mathrm{msec})$ stimulus durations. For lists of phonological associates, false recall (Experiment 2) was highest (.47) at the $20-\mathrm{msec}$ presentation duration, whereas for semantically related lists, false recall was highest (.25) at the longest duration. Ballardini et al. suggested that at the short 20-msec stimulus duration, participants have time to analyze perceptual features but do not have time to process lexical or semantic content. Consequently, perceptually based activation was sufficiently strong at the 20-msec duration to produce relatively high levels of false recall for lists of phonological associates, but the extremely short processing window did not allow for much semantic or conceptually based spreading activation, resulting in relatively low levels of false recall for semantic associates. The $250-\mathrm{msec}$ duration, in contrast, provided sufficient time for semantic processing and the spread of semantically based activation, resulting in more than a twofold increase in the incidence of false recall across stimulus duration for lists of semantic associates (from .11 at $20 \mathrm{msec}$ to .25 at $250 \mathrm{msec}$ ).

Chan et al. (2005) also reported findings consistent with differences in the nature of activation for lists of semantic and phonological associates. In their study (Experiment 2), Chan et al. factorially crossed list type (semantic vs. phonological associates) with task instruction (attend to the meaning of words vs. attend to the sound of the words) using a repeated measures design. Thus, participants were asked to study lists of phonological associates with instructions to attend to meaning for half of these lists and instructions to attend to sound for the other half (with complementary conditions for lists of semantic associates). Chan et al. suggested that, if the nature of activation differs for lists of semantic and phonological associates, attention to sound should increase false memories for lists of phonological associates, whereas attention to meaning should promote false memories for semantically, but not phonologically, related lists. Their findings demonstrated exactly this type of crossover interaction, with meaning-based instructions leading to greater false recognition of semantic associates and with sound-based instructions yielding more false memories for lists of phonological associates.

The behavioral results of Chan et al. (2005) supporting differences in the nature of activation produced by lists of semantic and phonological associates are also consistent with neuroimaging data (McDermott, Petersen, Watson, \& Ojemann, 2003) demonstrating anatomically distinct activation for the two list types. McDermott et al. used a procedure similar to that of Chan et al., in which participants in an fMRI scanner were shown lists of phonological and semantic associates and were instructed to attend to either meaning (semantic lists) or rhyme (phonological lists) among the associates. Although some regions were activated equally during presentation of both list types, a number of other regions were preferentially activated following one or the other type of associate. McDermott et al. suggested that the pattern of results was consistent with subtle differences in both the locus and magnitude of activation produced by lists of semantic and phonological associates.

Finally, one finding from the present study that is consistent with differences in the nature of activation resulting from presentation of semantic and phonological associates is that, with one exception (false recognition without prior recall in Experiment 1), veridical memory was consistently higher following presentation of lists of semantic associates than following lists of phonological associates. One explanation for this difference is that participants engage in deeper conceptual-level processing for lists of semantic associates, leading to increased recall of items that were actually presented on the list, as compared with the shallower perceptually based activation that results from studying lists of phonological associates.

Taken together, findings from the present and previous research suggest that differences in the nature of activation processes can explain at least partially the absence of correlations between semantic and phonological false memories. Note that this proposal is consistent with other studies (Bölte \& Coenen, 2002; Cronk, 2001; Mandler, Graf, \& Kraft, 1986; Overson \& Mandler, 1987) demonstrating independence between the mechanisms mediating phonological and semantic priming. For instance, Cronk conducted a lexical decision experiment in which participants received semantic primes, phonological primes, or both semantic and phonological primes to target items. The findings from this study indicated statistically inde- 
pendent effects of semantic and phonological priming. Some studies (Cronk, 2001; Zhou \& Marslen-Wilson, 2000) have reported differences in both the magnitude and time course of semantic and phonological priming. Thus, although additional research is required to make definitive statements about the mechanisms mediating semantic and phonological false memories, findings from the present study along with results from previous investigations converge to support qualitative differences in the nature of activation as one factor contributing to the distinction.

In attributing differences between phonological and semantic false memories to distinct types of activation, it is important to note that an alternative account for the present findings is a dissociation in the cognitive functions underlying each type of memory error. That is, the activationdifference account places the locus of the low correlations between semantic and phonological false memories at the level of the type of activation produced by the different lists, but suggests that the basic pathways - activation followed by errors in source monitoring - are the same. It is possible, however, that each list type engages different pathways in generating false memories and the failure to find correlations between the two reflects the engagement of entirely different cognitive functions. Given the similarities in list construction and testing procedures, along with the extant literature on differences between phonological and semantic activation (Chan et al., 2005; Watson et al., 2003), we believe this to be a less likely possibility, but the present data cannot exclude such an alternative account.

In summary, the present results complement and extend the findings of previous investigations (Chan et al., 2005; Watson et al., 2003) that have examined differences in the nature of activation produced by lists of semantic and phonological associates. Specifically, to our knowledge, the findings from Experiment 1 are the first direct evidence for at least partial independence of the mechanisms mediating false memories generated with lists of semantic versus phonological associates. Prior research into this topic has provided indirect evidence for differences in the nature of activation resulting from the two types of lists, but was not designed to correlate levels of false memory for pure lists of the two types of associates. The individual differences approach used in the present study provides further support for differences in the nature of activation produced by lists of semantic and phonological associates and extends this idea by demonstrating that one of the downstream consequences of such differential activation is a dissociation in the relationship between false memories generated by the two list types. More broadly, the results provide a partial blueprint for models of false memory by demonstrating that the architecture and dynamics of any such model will need to incorporate separate pathways for phonological and semantic activation to interact with ongoing memory processes in producing false memories. The challenge for future investigations will be to specify whether and how these different pathways intersect in order to develop a comprehensive model for false memories produced within the DRM paradigm. We view the present findings as a first step in this process, because they provide an important boundary condition for any such model.

\section{AUTHOR NOTE}

This research was supported by a grant from the Gustavus and Louise Pfeiffer Foundation to the second author. The authors thank Jennifer Dave for assistance with data collection. In addition, David Balota and Henry Roediger provided useful feedback on earlier versions of the manuscript. Correspondence concerning this article should be addressed to M. S. Sommers, Department of Psychology, Campus Box 1125, Washington University, One Brookings Dr., St. Louis, MO 631304899 (e-mail: msommers@wustl.edu).

\section{REFERENCES}

Ballardini, N., Yamashita, J. A., \& Wallace, W. P. (2008). Presentation duration and false recall for semantic and phonological associates. Consciousness \& Cognition, 17, 64-71.

Balota, D. A., Cortese, M. J., DucheK, J. M., Adams, D., RoediGer, H. L., III, MCDermott, K. B., \& Yerys, B. E. (1999). Veridical and false memories in healthy older adults and in dementia of the Alzheimer's type. Cognitive Neuropsychology, 16, 361-384.

Bölte, J., \& CoEnEN, E. (2002). Is phonological information mapped onto semantic information in a one-to-one manner? Brain \& Language, 81, 384-397.

Budson, A. E., Sullivan, A. L., Daffner, K. R., \& Schacter, D. L. (2003). Semantic versus phonological false recognition in aging and Alzheimer's disease. Brain \& Cognition, 51, 251-261.

Chan, J. C., McDermott, K. B., Watson, J. M., \& Gallo, D. A. (2005). The importance of material-processing interactions in inducing false memories. Memory \& Cognition, 33, 389-395.

Cronk, B. C. (2001). Phonological, semantic, and repetition priming with homophones. Journal of Psycholinguistic Research, 30, 265-378.

DEESE, J. (1959). On the prediction of occurrence of particular verbal intrusions in immediate recall. Journal of Experimental Psychology, 58, 17-22

GALLO, D. A. (2004). Using recall to reduce false recognition: Diagnostic and disqualifying monitoring. Journal of Experimental Psychology: Learning, Memory, \& Cognition, 30, 120-128.

Gallo, D. A., \& Roediger, H. L., III (2002). Variability among word lists in eliciting memory illusions: Evidence for associative activation and monitoring. Journal of Memory \& Language, 47, 469-497.

Gallo, D. A., \& Roediger, H. L., III (2003). The effects of associations and aging on illusory recollection. Memory \& Cognition, 31, 1036-1044.

Geraci, L., \& McCABE, D. P. (2006). Examining the basis for illusory recollection: The role of remember/know instructions. Psychonomic Bulletin \& Review, 13, 466-473.

Kensinger, E. A., \& SCHACTER, D. L. (1999). When true memories suppress false memories: Effects of ageing. Cognitive Neuropsychology, 16, 399-415.

LucE, P. A., \& Pisoni, D. B. (1998). Recognizing spoken words: The neighborhood activation model. Ear \& Hearing, 19, 1-36.

Mandler, G., Graf, P., \& Kraft, D. (1986). Activation and elaboration effects in recognition and word priming. Quarterly Journal of Experimental Psychology, 38A, 645-662.

Marslen-Wilson, W. D. (1987). Functional parallelism in spoken word-recognition. Cognition, 25, 71-102.

McDermotт, K. B. (1996). The persistence of false memories in list recall. Journal of Memory \& Language, 35, 212-230.

McDermott, K. B., Petersen, S. E., Watson, J. M., \& Ojemann, J. G. (2003). A procedure for identifying regions preferentially activated by attention to semantic and phonological relations using functional magnetic resonance imaging. Neuropsychologia, 41, 293-303.

McDermotт, K. B., \& Watson, J. M. (2001). The rise and fall of false recall: The impact of presentation duration. Journal of Memory \& Language, 45, 160-176.

NoRRIS, D. (1994). Shortlist: A connectionist model of continuous speech recognition. Cognition, 52, 189-234.

Overson, C., \& MANDLER, G. (1987). Indirect word priming in con- 
nected semantic and phonological contexts. Bulletin of the Psychonomic Society, 25, 229-232.

Roediger, H. L., III, Balota, D. A., \& Watson, J. M. (2001). Spreading activation and arousal of false memories. In H. L. Roediger III \& J. S. Nairne (Eds.), The nature of remembering: Essays in honor of Robert G. Crowder (pp. 95-115). Washington, DC: American Psychological Association.

Roediger, H. L., III, \& McDermott, K. B. (1995). Creating false memories: Remembering words not presented in lists. Journal of Experimental Psychology: Learning, Memory, \& Cognition, 21, 803-814.

Schacter, D. L., Verfaellie, M., \& Anes, M. D. (1997). Illusory memories in amnesic patients: Conceptual and perceptual false recognition. Neuropsychology, 11, 331-342.

Schacter, D. L., Verfaellie, M., \& Pradere, D. (1996). The neuropsychology of memory illusions: False recall and recognition in amnesic patients. Journal of Memory \& Language, 35, 319-334.

Sommers, M. S., \& HufF, L. M. (2003). The effects of age and dementia of the Alzheimer's type on phonological false memories. Psychology \& Aging, 18, 791-806.

Sommers, M. S., \& Lewis, B. P. (1999). Who really lives next door: Creating false memories with phonological neighbors. Journal of Memory \& Language, 40, 83-108.

Stadler, M. A., Roediger, H. L., III, \& McDermott, K. B. (1999). Norms for word lists that create false memories. Memory \& Cognition, 27, 494-500.

Steiger, J. H. (1980). Tests for comparing elements of a correlation matrix. Psychological Bulletin, 87, 245-251.

Tulving, E. (1985). Memory and consciousness. Canadian Psychology, 26, 1-12.
UNDERWOOD, B. J. (1965). False recognition produced by implicit verbal responses. Journal of Experimental Psychology, 70, 122-129.

Waldie, B. D., \& KwONG SeE, S. T. (2000). Remembering words never presented: False memory effects in dementia of the Alzheimer type. Aging, Neuropsychology, \& Cognition, 10, 281-297.

Wallace, W. P., Stewart, M. T., \& Malone, C. P. (1995). Recognition memory errors produced by implicit activation of word candidates during the processing of spoken words. Journal of Memory \& Language, 34, 417-439.

Wallace, W. P., Stewart, M. T., Sherman, H. L., \& Mellor, M. D. (1995). False positives in recognition memory produced by cohort activation. Cognition, 55, 85-113.

Watson, J. M., Balota, D. A., \& Roediger, H. L., III (2003). Creating false memories with hybrid lists of semantic and phonological associates: Over-additive false memories produced by converging associative networks. Journal of Memory \& Language, 49, 95-118.

Watson, J. M., Balota, D. A., \& Sergent-Marshall, S. D. (2001). Semantic, phonological, and hybrid veridical and false memories in healthy older adults and in individuals with dementia of the Alzheimer type. Neuropsychology, 15, 254-268.

Zhou, X., \& MARsLen-Wilson, W. (2000). The relative time course of semantic and phonological activation in reading Chinese. Journal of Experimental Psychology: Learning, Memory, \& Cognition, 26, $1245-1265$.

(Manuscript received February 1, 2008; revision accepted for publication August 2, 2008.) 